\title{
New Kids on the Block
}

\section{The Emerging Role of Apolipoproteins in the Pathogenesis and Treatment of Asthma}

\author{
Xianglan Yao, MD, PhD; Alan T. Remaley, MD, PhD; and Stewart J. Levine, MD, FCCP
}

\begin{abstract}
New treatments are needed for patients with severe asthma. We hypothesized that a clinically relevant experimental model of house dust mite (HDM)-induced murine asthma could be used to discover new pathways that regulate disease severity. In HDM-challenged mice, genome-wide expression profiling of the asthmatic lung transcriptome identified apolipoprotein $\mathrm{E}(\mathrm{apoE})$ as a steroid-unresponsive gene with persistently upregulated expression despite dexamethasone treatment. ApoE and low-density lipoprotein receptor (LDLR) knockout mice were used to demonstrate that apoE, which is produced by lung macrophages, functions in a paracrine fashion by binding to LDLRs expressed on ciliated airway epithelial cells, to negatively modulate airway hyperreactivity, mucin gene expression, and goblet cell hyperplasia. Furthermore, administration of an apoE mimetic peptide, which corresponded to the LDLR-binding domain of apoE, prevented the induction of airway inflammation, airway hyperreactivity, and goblet cell hyperplasia in HDM-challenged apoE knockout mice. This suggests that therapeutic strategies that activate the apoE-LDLR pathway, such as apoE mimetic peptides, may represent a novel treatment approach for patients with asthma. Similarly, we showed that administration of a 5A apolipoprotein A-I mimetic peptide attenuated the induction of HDM-mediated asthma in mice. These preclinical data suggest that apoE and apoA-I mimetic peptides might be developed into alternative treatments for patients with severe asthma. Future clinical trials will be required to determine whether inhaled apolipoprotein $\mathrm{E}$ or apolipoprotein A-I mimetic peptides are effective for the treatment of severe asthma, including patients with phenotypes that lack effective therapeutic options.

CHEST 2011; 140(4):1048-1054
\end{abstract}

Abbreviations: ABCA1 = ATP-binding cassette transporter A1; AHR = airway hyperreactivity; apoA-I = apolipoprotein $\mathrm{A}-\mathrm{I}$; apoE $=$ apolipoprotein $\mathrm{E} ; \mathrm{HDM}=$ house dust mite; LABA = long-acting $\boldsymbol{\beta}_{2}$-agonist; LDLR = low-density lipoprotein receptor; $\mathrm{Th}=\mathrm{T}$ helper

$\mathbf{N}^{\mathrm{e}}$ ew therapeutic approaches are needed for the $5 \%$ to $10 \%$ of patients with asthma who have severe disease. ${ }^{1}$ The 2007 Expert Panel 3 Report from the National Heart, Lung, and Blood Institute's National Asthma Education and Prevention Program recommends that oral corticosteroids be added if

Manuscript received January 19, 2011; revision accepted January 25, 2011.

Affiliations: From the Cardiovascular and Pulmonary Branch, National Heart, Lung, and Blood Institute, National Institutes of Health, Bethesda, MD.

Funding/Support: This study was funded by the Division of Intramural Research, National Heart, Lung, and Blood Institute, National Institutes of Health.

Correspondence to: Stewart J. Levine, MD, FCCP, Cardiovascular and Pulmonary Branch, National Heart, Lung, and Blood Institute, National Institutes of Health, Bldg 10, Room 6D03, MSC 1590, Bethesda, MD 20892-1590; e-mail: levines@nhlbi.nih.gov patients are persistently symptomatic despite high doses of inhaled corticosteroids plus long-acting $\beta_{2}$-agonists (LABAs). ${ }^{2}$ Corticosteroids, however, can be associated with significant adverse effects, such as weight gain, diabetes, impaired host defense, osteoporosis, and aseptic necrosis. Omalizumab (Xolair), a monoclonal anti-IgE antibody, can also be used to reduce the frequency of asthma exacerbations and the dose of inhaled corticosteroids, but requires parenteral administration and is limited to patients with elevated blood IgE levels. ${ }^{3}$ Bronchial thermoplasty

(C) 2011 American College of Chest Physicians. Reproduction of this article is prohibited without written permission from the American College of Chest Physicians (http://www.chestpubs.org/ site/misc/reprints.xhtml).

DOI: $10.1378 /$ chest.11-0158 

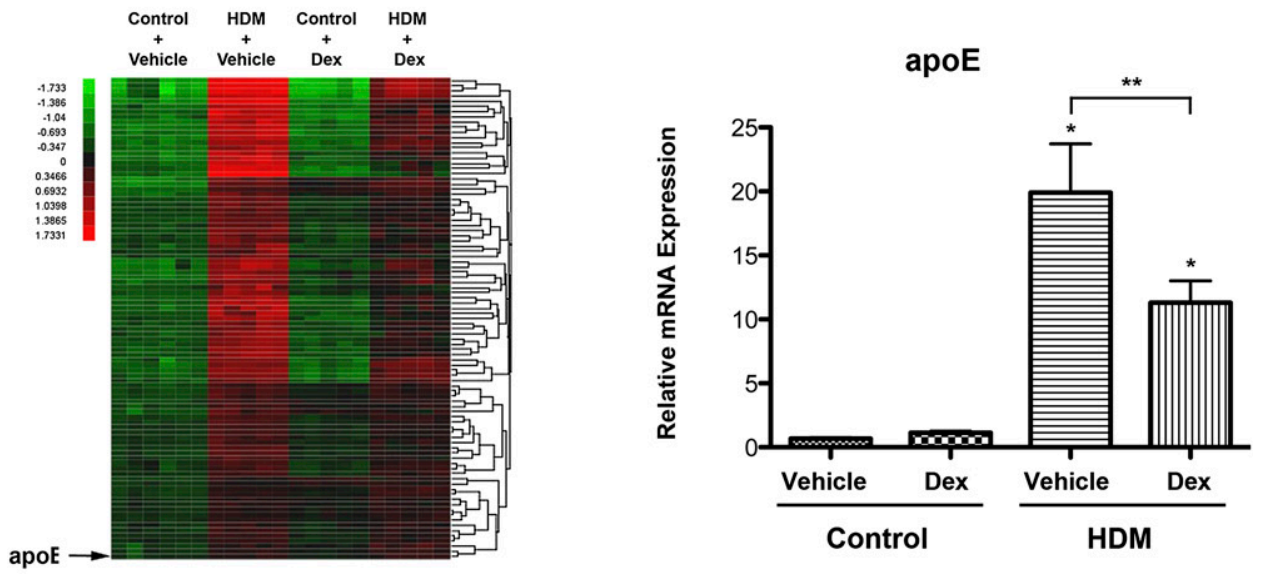

C

ApoE (130 - 149) Mimetic Peptide

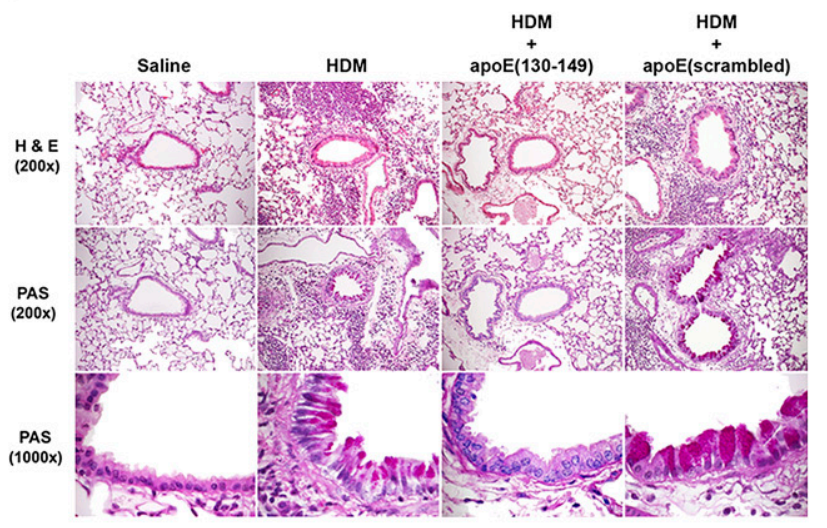

D

5A ApoA-I Mimetic Peptide

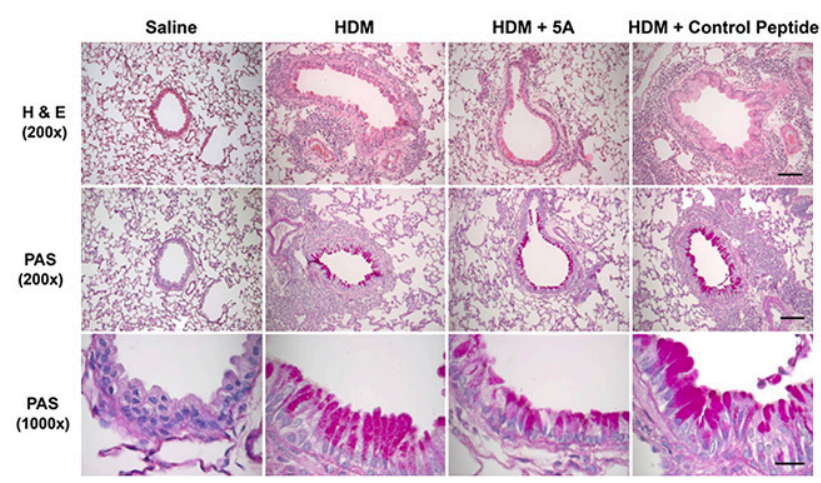

FIGURE 1. A and B, Identification of apoE as a corticosteroid-unresponsive gene in an experimental murine model of HDM-induced asthma. Asthma was induced in wild-type A/I mice by daily nasal administration of HDM or saline (control) 5 days per week for 6 consecutive weeks. Mice were treated with $1 \mathrm{mg} / \mathrm{kg}$ dexamethasone (dex) or saline (vehicle), which was administered via an osmotic minipump, during weeks 4 to 6 . A, Hierarchical cluster analysis of lung mRNA transcripts that were upregulated twofold or greater in the HDM + vehicle group as compared with the control + vehicle group. mRNA transcripts that were upregulated twofold or greater in the HDM + dex group were considered corticosteroid-unresponsive. B, Lung mRNA expression of apoE was assessed by quantitative real-time reverse transcription-polymerase chain reaction and presented as relative mRNA expression. C and D, ApoE and apoA-I mimetic peptides attenuate the induction of airway inflammation and goblet cell hyperplasia in an experimental murine model of HDM-induced asthma. C, Administration of the apoE(130-149) mimetic peptide to apoE knockout mice attenuates airway inflammation and goblet cell hyperplasia. Histologic sections of lung were stained with $\mathrm{H} \& \mathrm{E}$ or PAS and images obtained at $\times 200$ or $\times 1,000$. D, Administration of the $5 \mathrm{~A}$ apoA-I mimetic peptide to wild-type A/J mice attenuates 
is a new treatment option that involves several bronchoscopies to deliver thermal energy that ablates airway smooth muscle. ${ }^{4}$ This procedure has recently been approved by the US Food and Drug Administration for adult patients with asthma who have persistent symptoms despite inhaled corticosteroids plus LABAs. Although these advances have given patients with severe asthma additional treatment options, it would be advantageous for clinicians to be able to offer additional therapeutic approaches that are efficacious and do not require parenteral administration or invasive procedures.

\section{Using a Murine Model of Experimental House Dust Mite-Induced Asthma TO IDENTIFY NEW MECHANISMS of Disease Pathogenesis}

Asthma has a complex pathogenesis that is manifested by airway inflammation, airway hyperreactivity (AHR), and airway remodeling responses.,3,6 Our laboratory hypothesized that a clinically relevant experimental model of house dust mite (HDM)induced murine asthma could be used to identify pathways that regulate disease severity. ${ }^{7}$ HDM (Dermatophagoides pteronyssinus) was selected to induce asthma because it is a common aeroallergen that is an environmental trigger and risk factor for the development of persistent asthma. ${ }^{78} \mathrm{HDM}$ is a complex mixture of proteins and lipopolysaccharide that induces airway inflammation via allergic and nonallergic mechanisms. ${ }^{9-11}$ Furthermore, the mechanism of HDM-induced asthma depends on toll-like receptor 4 signaling by airway epithelial cells, which activates both innate and adaptive immune responses. ${ }^{12}$ In this model system, nasal HDM challenges to wildtype $\mathrm{A} / \mathrm{J}$ mice, which is a strain that has enhanced susceptibility to asthma, induced airway inflammation, airway remodeling, and AHR. ${ }^{13,14}$ We reasoned that we could use this model system to identify pulmonary genes that are upregulated in response to HDM challenge and remain persistently upregulated despite corticosteroid treatment. Consistent with this concept, genome-wide expression profiling of the asthmatic lung transcriptome identified apolipoprotein $\mathrm{E}$ (apoE) as one of 68 candidate steroid-unresponsive genes with persistently increased expression despite dexamethasone treatment in HDMchallenged mice, which was confirmed by real-time quantitative polymerase chain reaction (Figs 1A, 1B).
ApoE Is an ENDOgenous Negative Regulator of AHR and Goblet Cell Hyperplasia in MURINE EXPERIMENTAL HDM-INDUCED ASTHMA

Although apolipoproteins play a key role in lipid metabolism by serving as structural components of plasma lipoproteins, a role for these proteins in modulating asthma pathogenesis and disease severity had not previously been identified. ${ }^{15}$ ApoE is a protein component of very-low-density lipoproteins, chylomicron remnants, and intermediate-density lipoproteins, as well as a subclass of high-density lipoproteins, that mediates high-affinity binding of apoE-containing lipoprotein particles to the low-density lipoprotein receptor (LDLR). ${ }^{16,17}$ ApoE plays an important role in cholesterol homeostasis, as evidenced by the finding that apoE knockout (apoE $\left.{ }^{-/-}\right)$mice develop hypercholesterolemia and spontaneous atherosclerosis. ${ }^{18}$ The function of apoE, however, is not limited to cholesterol transport but has also been implicated in Alzheimer disease, host susceptibility to infection, and presentation of lipid antigens by antigenpresenting cells. ${ }^{17,19,20}$ ApoE has also been found to modulate lung morphogenesis, as apo $\mathrm{E}^{-1-}$ mice have reduced developmental alveologenesis and abnormal pulmonary function with increased airway resistance, as well as high dynamic and static compliance. ${ }^{21}$

To characterize the role of apoE in asthma pathogenesis, we used a genetic approach. First, we showed that apoE is expressed by macrophages in the lung. Next, apoE ${ }^{-1-}$ mice received nasal HDM challenges to induce experimental asthma and their phenotype was compared with wild-type mice. ${ }^{14}$ In this experimental murine model of HDM-induced asthma, AHR, goblet cell hyperplasia, and mucin (Muc5AC) gene expression were increased in apoE $\mathrm{E}^{-1-}$ mice, whereas airway inflammation was not affected. Thus, using this experimental murine model of HDM-induced asthma, a novel function was identified for apoE as an endogenous negative regulator of AHR and goblet cell hyperplasia.

Additional experiments assessed whether the asthmatic phenotype of apoE $\mathrm{E}^{-/-}$mice could be rescued by administration of an apoE mimetic peptide. The apoE protein, which is composed of 299 amino acids, has a helical horseshoe configuration that contains two distinct functional domains. ${ }^{17}$ The amino-terminus contains an LDLR-binding domain, which corresponds to amino acids 134 to 150 , whereas the carboxy terminus contains a lipid-binding domain, which corresponds to amino acids 244 to 272 of the apoE protein

airway inflammation and goblet cell hyperplasia. Histologic sections of lung were stained with $\mathrm{H} \& \mathrm{E}$ or PAS stains and images obtained at $\times 200$ or $\times 1,000$. apoA-I $=$ apolipoprotein A-I; apoE $=$ apolipoprotein $\mathrm{E}$; Dex = dexamethasone; $\mathrm{H} \& \mathrm{E}=$ hematoxylin and eosin; $\mathrm{HDM}=$ house dust mite; PAS = periodic acid-Schiff. (A-C, reprinted with permission of the American Thoracic Society ${ }^{14}$; D, reprinted with permission from The American Association of Immunologists, Inc. ${ }^{45}$ ) 

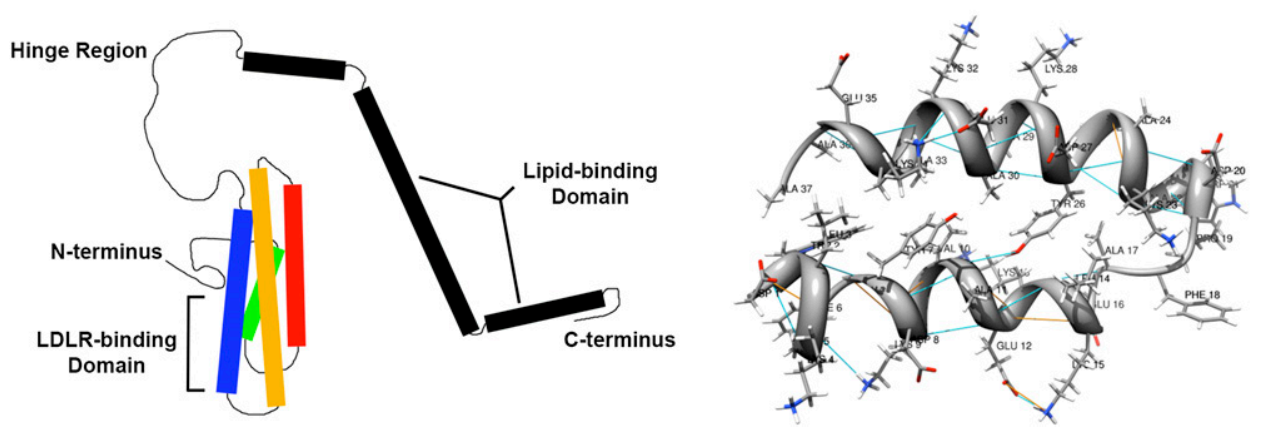

Figure 2. Structures of full-length apoE and the 5A apoA-I mimetic peptide. A, Protein structure of apoE. A model of the protein structure of apolipoprotein $\mathrm{E}$ is shown. The amino-terminus ( $\mathrm{N}$-terminus), which contains the LDLR-binding domain, is separated from the carboxy-terminus (C-terminus), which contains the lipid-binding domain, by a hinge region. The boxes indicate amphipathic $\alpha$-helices and the amino-terminus forms a four-helix antiparallel bundle. The apoE(130-149) mimetic peptide corresponds to amino acids 130 to 149 of full-length apoE, which is located in the LDLR-binding domain in helix \#4 of the amino-terminal antiparallel bundle. B, Structure of the 5A apoA-I mimetic peptide. The $5 \mathrm{~A}$ peptide is a 37 amino acid long bihelical peptide, containing a proline between the two amphipathic helices. 5 Alanine substitutions are made in the hydrophobic face of the second helix to reduce its lipid affinity. LDLR = low-density lipoprotein receptor. See Figure 1 legend for expansion of other abbreviation. (A, adapted with permission from the American Society for Biochemistry and Molecular Biology. $\left.{ }^{17}\right)$

(Fig 2A). Both of these domains exist in amphipathic helical parts of the protein, which is a structural motif that enables apolipoproteins to bind to lipids. It has been recognized that peptides corresponding to the LDLR-binding domain of apoE are biologically active and can suppress experimental models of inflammation and neurotoxicity as well as mediate antiviral effects. ${ }^{22-25}$ Furthermore, apoE mimetic peptides have been shown to have beneficial effects in experimental animal models of septic shock, ocular inflammation, and neurologic disease. ${ }^{24,26,27}$ We showed that systemic administration of an apoE(130-149) mimetic peptide, which corresponded to amino acids 130 to 149 of the apoE LDLR-binding domain, rescued the phenotype of enhanced AHR and goblet cell hyperplasia in HDM-challenged apoE $\mathrm{E}^{-/-}$mice. Furthermore, the apoE(130-149) mimetic peptide significantly attenuated the induction of eosinophilic airway inflammation (Fig 1C), IgE production, and expression of T-helper (Th) 2 (IL-4, IL-13) and Th17 (IL-17A) cytokines, as well as chemokines that mediate the chemotaxis of eosinophils and T cells (CCL7, CCL11, CCL17).

The apoE(130-149) mimetic peptide was also used to characterize the role of the LDLR in experimental HDM-induced asthma. First, ciliated airway epithelial cells were found to express the LDLR. Second, we reasoned that if the LDLR were the relevant receptor for apoE in the airway, then the phenotype of $\mathrm{LDLR}^{-/-}$mice should recapitulate that of apoE $\mathrm{E}^{-/-}$ mice.

Similar to apoE $\mathrm{E}^{-/-}$mice, HDM-challenged $\mathrm{LDLR}^{-/-}$ mice displayed enhanced AHR, mucin gene expres- sion, and goblet cell hyperplasia as compared with wild-type mice, whereas airway inflammatory responses were not altered. Administration of the apoE(130-149) mimetic, however, did not rescue the phenotype of enhanced AHR and goblet cell hyperplasia in $\mathrm{LDLR}^{-/-}$ knockout mice, which is consistent with the conclusion that the LDLR mediates the negative regulatory effects of apoE on AHR and goblet cell hyperplasia.

To summarize our findings, apoE, which is produced by lung macrophages, was found to function in a paracrine fashion by binding LDLRs expressed on ciliated airway epithelial cells and thereby negatively modulate AHR, mucin gene expression, and goblet cell hyperplasia in a murine model of HDMinduced asthma. Furthermore, administration of an apoE mimetic peptide was shown to prevent the induction of airway inflammation, airway hyperreactivity, and goblet cell hyperplasia in apo: $\mathrm{E}^{-/-}$mice. Taken together, these data demonstrate that therapeutic strategies that activate the apoE-LDLR pathway, such as apoE mimetic peptides, may represent a novel treatment approach for patients with asthma.

\section{The 5A Apolipoprotein A-I Mimetic PePtide AtTENUATES THE INDUCTION OF EXPERIMENTAL HDM-INDUCED ASTHMA}

We next hypothesized that apolipoprotein A-I (apoA-I) mimetic peptides, which like apoE contain a tandem array of amphipathic helices, might be similarly effective at attenuating disease severity in asthma. ApoA-I is a key component of high-density 
lipoproteins that mediate reverse cholesterol transport from cells via binding to the ATP-binding cassette transporter A1 (ABCA1).28,29 ApoA-I also has antiinflammatory, antioxidant, and antithrombotic properties. ${ }^{30}$ Furthermore, apoA-I attenuates immune cell functions that may be important for asthma, including dendritic cell differentiation and maturation, T-cell activation, and neutrophil degranulation. ${ }^{31-33}$ A limitation regarding the therapeutic use of apoA-I, however, is the difficulty in generating sufficient quantities of recombinant protein that are free of lipopolysaccharide contamination. ${ }^{28}$ Thus, apoA-I mimetic peptides have been developed that recapitulate the secondary structure of the native apoA-I protein, which contains 10 amphipathic $\alpha$-helices, and have cardioprotective, antioxidant, and antiinflammatory properties. ${ }^{28}$ ApoA-I mimetic peptides have been shown to have beneficial effects in experimental animal model systems of atherosclerosis, Alzheimer disease, ovarian cancer, septic shock, sickle cell disease, diabetes, obesity, and heart transplant rejection. ${ }^{28,34-41}$ Furthermore, apoA-I mimetic peptides have advanced to clinical trials of patients with coronary artery disease. ${ }^{42}$

Because airway inflammation is a key pathogenic manifestation of asthma, we hypothesized that apoA-I mimetic peptides might also be used as a novel therapeutic approach for asthma. In our studies, we used the 5A apoA-I mimetic peptide, which is a bihelical amphipathic peptide that mediates cholesterol efflux and reduces atherosclerosis via the ABCA1 transporter (Fig 2B). ${ }^{29}$ A potential advantage of the $5 \mathrm{~A}$ apoA-I mimetic peptide over other apoA-I mimetic peptide constructs is that it is more specific for promoting cholesterol efflux from cells by the ABCA1 transporter because of its reduced hydrophobicity, which also makes the peptide less cytotoxic. ${ }^{29}$ The 5A apoA-I mimetic peptide has also been used to attenuate atherosclerosis, acute vascular inflammation, and oxidative stress in experimental animal models systems. ${ }^{43,44}$

In our experimental model of HDM-induced asthma, systemic administration of the $5 \mathrm{~A}$ peptide to wildtype $\mathrm{A} / \mathrm{J}$ mice attenuated the induction of the key pathogenic manifestations of asthma, including airway inflammation, airway hyperreactivity, and airway remodeling. ${ }^{45}$ In particular, the $5 \mathrm{~A}$ apoA-I mimetic peptide downregulated the induction of HDMinduced airway inflammation (Fig $1 \mathrm{D}^{45}$ ) by mechanisms that included the reduced expression of Th2 (IL-4, IL-5, IL-13) and Th17 (IL-17A) cytokines, the attenuated expression of chemokines that are chemotactic for $\mathrm{T}$ cells, dendritic cells, and eosinophils (CCL7, CCL11, CCL17, CCL24), and the diminished recruitment of alternatively activated macrophages. In contrast, the $5 \mathrm{~A}$ peptide did not reduce total serum
IgE levels, which suggested that the mechanism by which the $5 \mathrm{~A}$ peptide attenuates airway inflammation did not involve impaired allergic sensitization to HDM antigens. The 5A apoA-I mimetic peptide also attenuated the induction of AHR, as well as several of the key manifestations of airway remodeling, which included goblet cell hyperplasia and the expression of the Muc5AC mucin gene and Clca3, a calciumactivated chloride channel that is associated with the development of goblet cell hyperplasia. ${ }^{46}$ Similarly, the $5 \mathrm{~A}$ peptide reduced the expression of genes associated with subepithelial collagen deposition, including type 1 (Colla1) and type 3 (Col3a1) collagens. ${ }^{47}$ Taken together, these results show that administration of a 5A apoA-I mimetic peptide attenuates the induction of many of the key pathogenic features of HDM-induced asthma, including airway inflammation, airway hyperreactivity, and airway remodeling. Recently, another apoA-I mimetic peptide, D4F, which was designed to protect against inflammation from lipid oxidation, has also been shown to decrease airway hyperresponsiveness and inflammation in an ovalbumin sensitization model of asthma in mice. ${ }^{48}$

\section{Future Directions: Development of ApoE and ApoA-I Mimetic Peptides as Novel Therapeutic Approaches FOR THE TREATMENT OF ASTHMA}

We have used clinically relevant murine models of experimental HDM-induced asthma to show that apoE and apoA-I mimetic peptides can attenuate the induction of airway inflammation, airway hyperreactivity, and goblet cell hyperplasia (Fig 3). An

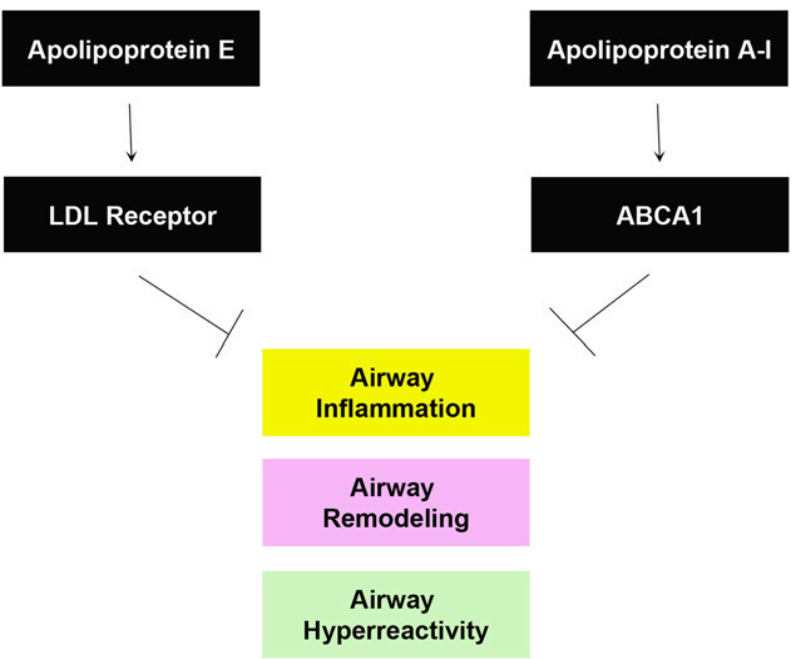

Figure 3. ApoE and apoA-I pathways in the lung attenuate the induction of experimental house dust mite-induced asthma. $\mathrm{ABCA} 1=\mathrm{ATP}$-binding cassette transporter $\mathrm{A} 1 ; \mathrm{LDL}=$ low-density lipoprotein. See Figure 1 for expansion of the other abbreviations. 
important future direction for our laboratory is to advance these findings from the "bench-to-thebedside" and initiate clinical trials of apoE and apoA-I mimetic peptides to determine whether these approaches represent efficacious and safe treatments for patients with asthma, especially those with severe or refractory disease. Furthermore, we plan to develop inhalational preparations of apoE and apoA-I mimetic peptides that will allow site-directed delivery to the lungs of patients with asthma and thereby potentially avoid or limit systemic distribution and adverse effects. An additional benefit of inhaled apoE and apoA-I mimetic peptides is that administration would not require either parenteral administration or invasive procedures.

In particular, we envision a potential role for apolipoprotein mimetic peptides as new treatments for patients with severe asthma, based on their targeting of novel pathways that modulate asthma pathogenesis. If efficacious, apolipoprotein mimetic peptides might be developed either as an alternative to oral corticosteroids or as an adjunctive medication that permits a reduction in corticosteroid dose. Although the apoE and apoA-I mimetic peptides appear to be broadly effective in experimental murine models, it is not yet known whether they will be efficacious in a general population of patients with severe asthma or will need to be targeted to patients with specific severe asthma phenotypes. ${ }^{49}$ For example, since the endogenous apoE-LDLR pathway primarily regulates AHR and goblet cell hyperplasia, apoE mimetic peptides might be an efficacious approach for the treatment of patients with severe asthma with a paucigranulocytic inflammatory phenotype, who have symptoms in the absence of airway inflammation and would not be expected to benefit from the antiinflammatory effects of corticosteroids. ${ }^{49}$ Similarly, studies may be aimed at assessing whether apolipoprotein E or apolipoprotein A-I mimetic peptides can decrease airway inflammation in patients with neutrophil-predominant asthma, which has limited responsiveness to inhaled corticosteroids. ${ }^{50}$ Thus, future clinical trials will be required to determine whether inhaled apolipoprotein $\mathrm{E}$ or apolipoprotein A-I mimetic peptides can be developed into novel therapeutic approaches for the treatment of severe asthma, especially for patients with phenotypes that do not have effective therapeutic options.

\section{ACKNOWLEDGMENTS}

Financial/nonfinancial disclosures: The authors have reported to CHEST the following conflicts of interest: Dr Remaley is the holder of a provisional patent regarding the 5A apoA-I mimetic peptide. Dr Levine is the holder of two patents that are not related to the topic of this article. Dr Yao has reported to CHEST that no potential conflicts of interest exist with any companies/organizations whose products or services may be discussed in this article.

Other contributions: We thank Alexander Andrianov, PhD, for creating the model of the $5 \mathrm{~A}$ peptide structure.

\section{REFERENCES}

1. Moore WC, Bleecker ER, Curran-Everett D, et al; National Heart, Lung, Blood Institute's Severe Asthma Research Program. Characterization of the severe asthma phenotype by the National Heart, Lung, and Blood Institute's Severe Asthma Research Program. J Allergy Clin Immunol. 2007; 119(2):405-413.

2. National Asthma Education and Prevention Program. National Heart, Lung, and Blood Institute, National Institutes of Health, US Department of Health and Human Services Expert Panel Report 3: Guidelines for the Diagnosis and Management of Asthma. Bethesda, MD: National Institutes of Health; 2007. NIH publication 07-4051.

3. Fanta CH. Asthma. N Engl J Med. 2009;360(10):1002-1014.

4. Castro M, Rubin AS, Laviolette M, et al; AIR2 Trial Study Group. Effectiveness and safety of bronchial thermoplasty in the treatment of severe asthma: a multicenter, randomized, double-blind, sham-controlled clinical trial. Am J Respir Crit Care Med. 2010;181(2):116-124.

5. Barnes PJ. The cytokine network in asthma and chronic obstructive pulmonary disease. J Clin Invest. 2008;118(11):3546-3556.

6. Bergeron C, Al-Ramli W, Hamid Q. Remodeling in asthma. Proc Am Thorac Soc. 2009;6(3):301-305.

7. Johnson JR, Wiley RE, Fattouh R, et al. Continuous exposure to house dust mite elicits chronic airway inflammation and structural remodeling. Am J Respir Crit Care Med. 2004; 169(3):378-385.

8. Sears MR, Greene JM, Willan AR, et al. A longitudinal, population-based, cohort study of childhood asthma followed to adulthood. N Engl J Med. 2003;349(15):1414-1422.

9. De Alba J, Raemdonck K, Dekkak A, et al. House dust mite induces direct airway inflammation in vivo: implications for future disease therapy? Eur Respir J. 2010;35(6):1377-1387.

10. Lambrecht BN, Hammad H. Biology of lung dendritic cells at the origin of asthma. Immunity. 2009;31(3):412-424.

11. Thomas WR, Smith WA, Hales BJ, Mills KL, O'Brien RM. Characterization and immunobiology of house dust mite allergens. Int Arch Allergy Immunol. 2002;129(1):1-18.

12. Hammad H, Chieppa M, Perros F, Willart MA, Germain RN, Lambrecht BN. House dust mite allergen induces asthma via Toll-like receptor 4 triggering of airway structural cells. Nat Med. 2009;15(4):410-416.

13. Levitt RC, Mitzner W. Expression of airway hyperreactivity to acetylcholine as a simple autosomal recessive trait in mice. FASEB J. 1988;2(10):2605-2608.

14. Yao X, Fredriksson K, Yu ZX, et al. Apolipoprotein E negatively regulates house dust mite-induced asthma via a lowdensity lipoprotein receptor-mediated pathway. Am J Respir Crit Care Med. 2010;182(10):1228-1238.

15. Mahley RW, Bersot TP. Chapter 35. Drug therapy for hypercholesterolemia and dyslipidemia. In: Brunton LL, Lazo IS, Parker KL, eds. Goodman \& Gilman's The Pharmacological Basis of Therapeutics. 11th ed. Columbus, OH: The McGrawHill Companies, Inc. 2010. http://www.accessmedicine.com/ content.aspx?aID=945881. Accessed December 6, 2010.

16. Goldstein JL, Brown MS. The LDL receptor. Arterioscler Thromb Vasc Biol. 2009;29(4):431-438.

17. Mahley RW, Weisgraber KH, Huang Y. Apolipoprotein E: structure determines function, from atherosclerosis to Alzheimer's disease to AIDS. J Lipid Res. 2009;50(suppl): S183-S188. 
18. Zhang SH, Reddick RL, Piedrahita JA, Maeda N. Spontaneous hypercholesterolemia and arterial lesions in mice lacking apolipoprotein E. Science. 1992;258(5081):468-471.

19. Bu G. Apolipoprotein E and its receptors in Alzheimer's disease: pathways, pathogenesis and therapy. Nat Rev Neurosci. 2009;10(5):333-344.

20. van den Elzen P, Garg S, León L, et al. Apolipoproteinmediated pathways of lipid antigen presentation. Nature. 2005; 437(7060):906-910.

21. Massaro D, Massaro GD. ApoetmlUnc mice have impaired alveologenesis, low lung function, and rapid loss of lung function. Am J Physiol Lung Cell Mol Physiol. 2008;294(5): L991-L997.

22. Croy JE, Brandon T, Komives EA. Two apolipoprotein E mimetic peptides, ApoE(130-149) and ApoE(141-155)2, bind to LRP1. Biochemistry. 2004;43(23):7328-7335.

23. Dobson CB, Sales SD, Hoggard P, Wozniak MA, Crutcher KA. The receptor-binding region of human apolipoprotein $\mathrm{E}$ has direct anti-infective activity. J Infect Dis. 2006;193(3):442-450.

24. Lynch JR, Tang W, Wang H, et al. APOE genotype and an ApoE-mimetic peptide modify the systemic and central nervous system inflammatory response. J Biol Chem. 2003; 278(49):48529-48533.

25. Misra UK, Adlakha CL, Gawdi G, McMillian MK, Pizzo SV, Laskowitz DT. Apolipoprotein E and mimetic peptide initiate a calcium-dependent signaling response in macrophages. J Leukoc Biol. 2001;70(4):677-683.

26. Bhattacharjee PS, Neumann DM, Foster TP, et al. Effective treatment of ocular HSK with a human apolipoprotein E mimetic peptide in a mouse eye model. Invest Ophthalmol Vis Sci. 2008;49(10):4263-4268.

27. Laskowitz DT, McKenna SE, Song P, et al. COG1410, a novel apolipoprotein E-based peptide, improves functional recovery in a murine model of traumatic brain injury. J Neurotrauma. 2007;24(7):1093-1107.

28. Sethi AA, Amar M, Shamburek RD, Remaley AT. Apolipoprotein AI mimetic peptides: possible new agents for the treatment of atherosclerosis. Curr Opin Investig Drugs. 2007;8(3):201-212.

29. Sethi AA, Stonik JA, Thomas F, et al. Asymmetry in the lipid affinity of bihelical amphipathic peptides. A structural determinant for the specificity of ABCA1-dependent cholesterol efflux by peptides. J Biol Chem. 2008;283(47):32273-32282.

30. Florentin M, Liberopoulos EN, Wierzbicki AS, Mikhailidis DP. Multiple actions of high-density lipoprotein. Curr Opin Cardiol. 2008;23(4):370-378.

31. Blackburn WD Jr, Dohlman JG, Venkatachalapathi YV, et al. Apolipoprotein A-I decreases neutrophil degranulation and superoxide production. J Lipid Res. 1991;32(12):1911-1918.

32. Kim KD, Lim HY, Lee HG, et al. Apolipoprotein A-I induces IL-10 and PGE2 production in human monocytes and inhibits dendritic cell differentiation and maturation. Biochem Biophys Res Commun. 2005;338(2):1126-1136.

33. Wilhelm AJ, Zabalawi M, Grayson JM, et al. Apolipoprotein A-I and its role in lymphocyte cholesterol homeostasis and autoimmunity. Arterioscler Thromb Vasc Biol. 2009;29(6):843-849.

34. Su F, Kozak KR, Imaizumi S, et al. Apolipoprotein A-I (apoA-I) and apoA-I mimetic peptides inhibit tumor development in a mouse model of ovarian cancer. Proc Natl Acad Sci U S A. 2010;107(46):19997-20002.
35. Navab M, Anantharamaiah GM, Hama S, et al. Oral administration of an Apo A-I mimetic Peptide synthesized from $\mathrm{D}$-amino acids dramatically reduces atherosclerosis in mice independent of plasma cholesterol. Circulation. 2002;105(3): 290-292.

36. Ruan X, Li Z, Zhang Y, et al. Apolipoprotein A-I possesses an anti-obesity effect associated with increase of energy expenditure and upregulation of UCP1 in brown fat. J Cell Mol Med. 2011;15(4):763-772.

37. Zhang Z, Datta G, Zhang Y, et al. Apolipoprotein A-I mimetic peptide treatment inhibits inflammatory responses and improves survival in septic rats. Am J Physiol Heart Circ Physiol. 2009;297(2):H866-H873.

38. Ou J, Ou Z, Jones DW, et al. L-4F, an apolipoprotein A-1 mimetic, dramatically improves vasodilation in hypercholesterolemia and sickle cell disease. Circulation. 2003;107(18): 2337-2341.

39. Hsieh GR, Schnickel GT, Garcia C, Shefizadeh A, Fishbein MC, Ardehali A. Inflammation/oxidation in chronic rejection: apolipoprotein A-I mimetic peptide reduces chronic rejection of transplanted hearts. Transplantation. 2007;84(2):238-243.

40. Handattu SP, Garber DW, Monroe CE, et al. Oral apolipoprotein A-I mimetic peptide improves cognitive function and reduces amyloid burden in a mouse model of Alzheimer's disease. Neurobiol Dis. 2009;34(3):525-534.

41. Peterson SJ, Drummond G, Kim DH, et al. L-4F treatment reduces adiposity, increases adiponectin levels, and improves insulin sensitivity in obese mice. J Lipid Res. 2008;49(8): 1658-1669.

42. Bloedon LT, Dunbar R, Duffy D, et al. Safety, pharmacokinetics, and pharmacodynamics of oral apoA-I mimetic peptide $\mathrm{D}-4 \mathrm{~F}$ in high-risk cardiovascular patients. J Lipid Res. 2008;49(6):1344-1352.

43. Amar MJ, D’Souza W, Turner S, et al. 5A apolipoprotein mimetic peptide promotes cholesterol efflux and reduces atherosclerosis in mice. J Pharmacol Exp Ther. 2010;334(2): 634-641.

44. Tabet F, Remaley AT, Segaliny AI, et al. The 5A apolipoprotein A-I mimetic peptide displays antiinflammatory and antioxidant properties in vivo and in vitro. Arterioscler Thromb Vasc Biol. 2010;30(2):246-252.

45. Yao X, Dai C, Fredriksson K, et al. 5A, an apolipoprotein A-I mimetic peptide, attenuates the induction of house dust mite-induced asthma. J Immunol. 2011;186(1):576-583.

46. Nakanishi A, Morita S, Iwashita H, et al. Role of gob-5 in mucus overproduction and airway hyperresponsiveness in asthma. Proc Natl Acad Sci U S A. 2001;98(9):5175-5180.

47. Chu HW, Halliday JL, Martin RJ, Leung DY, Szefler SJ, Wenzel SE. Collagen deposition in large airways may not differentiate severe asthma from milder forms of the disease. Am J Respir Crit Care Med. 1998;158(6):1936-1944.

48. Nandedkar SD, Weihrauch D, Xu H, et al. D-4F, an apoA-1 mimetic, decreases airway hyperresponsiveness, inflammation, and oxidative stress in a murine model of asthma. J Lipid Res. 2011;52(3):499-508

49. Wenzel SE. Asthma: defining of the persistent adult phenotypes. Lancet. 2006;368(9537):804-813.

50. Berry M, Morgan A, Shaw DE, et al. Pathological features and inhaled corticosteroid response of eosinophilic and noneosinophilic asthma. Thorax. 2007;62(12):1043-1049. 